\title{
Análise histórica do atendimento pré-natal e condições de saúde de gestantes atendidas por uma unidade básica de saúde de Juiz de Fora
}

\author{
Thirza dos Santos Nicácio, Vanessa Monfardini Alves, Renata Maria Souza Oliveira, Michele \\ Pereira Netto
}

\begin{abstract}
Resumo
A assistência pré-natal é fundamental para se obter informações seguras a respeito do período gestacional, e através destas, detectar e acompanhar possíveis riscos. As condições de saúde materna podem gerar efeitos positivos ou negativos sobre a gestante e/ou o feto, visto que este precisa de nutrientes, provenientes da mãe, fundamentais para seu crescimento e desenvolvimento. A avaliação do estado nutricional auxilia nas orientações a serem feitas ao decorrer de toda gestação e precisa ser realizada em todas as consultas. Os indicadores do município de Juiz de Fora (JF) mostram que a principal causa de morbidade na mulher é gravidez, parto e puerpério. Em relação a nascimentos pode-se observar uma queda na taxa bruta de natalidade, aumento de partos cesáreos, maior percentual de prematuridade e percentual de peso baixo ao nascer com leve aumento no município. Diante do exposto, justifica-se a análise histórica do cuidado pré-natal na unidade de saúde do município. Caracterizar as condições de saúde de gestantes atendidas por uma Unidade de Básica de Saúde do bairro Santos Dumont (UBS-SD), JF-MG e sua evolução ao longo de 10 anos. Trata-se de um estudo retrospectivo de dados secundários, referente aos últimos 10 anos de gestantes atendidas na UBS-SD/JF-MG. Os dados foram coletados entre Janeiro e Junho de 2016. Foram coletados e analisados os dados referentes ao pré-natal nesse período, especialmente os dados relacionados com a alimentação e nutrição. Os dados foram tabulados e processadas no software SPSS, versão 17.0, por meio de análises descritivas básicas. Foram analisadas informações de 146 prontuários dentro do período de 10 anos. A média de idade das gestantes foi de $24,3+5,7$ anos. A maior parte $(65,8 \%)$ não relataram doenças pessoais pregressas à gestação, entre as que haviam histórico foram descritas com mais frequência, hipertensão e diabetes; $10,2 \%$ faziam uso de álcool na gestação e 7,8\% de tabaco. Em relação ao número de gestações anteriores, variou de 0 a 6 , sendo que 48,8\% eram primíparas. Das gestantes com dados antropométricos, no $1^{\circ}$ trimestre, constatou-se que, $39 \%$ estavam classificadas com obesidade, $26,2 \%$ com sobrepeso, através da análise do IMC. Sobre as queixas na gestação, $50 \%$ não relataram queixas na primeira consulta, entre as que relataram, as mais frequentes foram náuseas e enjoos. Apenas 50 gestantes tinham resultado de hemoglobina descritos no prontuário, entre estas a mediana de hemoglobina foi 12,5 $\mathrm{g} / \mathrm{dL}$, correspondendo a um total de $14 \%$ de anemia neste grupo. Das 48 gestantes com resultado de glicemia, $14,5 \%$ e 4,2\% apresentavam valores entre 90 e $110 \mathrm{mg} / \mathrm{dL}$ e maiores que $110 \mathrm{mg} / \mathrm{dL}$, respectivamente. Os resultados encontrados estão em consonância com a literatura, demonstrando a presença de diversos fatores de risco na gestação de impacto para o resultado da gestação. Neste sentido, é de fundamental importância o acompanhamento contínuo no pré-natal, para prevenir e tratar diversas complicações.
\end{abstract}

Descritores: Assistência pré-natal; Estado Nutricional; Unidade Básica de Saúde. 